\title{
Study on Influencing Factors and Control Strategies of Surgical Smoke Concentration Distribution
}

\author{
Jun Wu ${ }^{1}$, Henggen Shen ${ }^{1 *}$, Xiafei Zhan ${ }^{1}$, Yingjian $Z^{2} u^{2}$ \\ ${ }^{1}$ College of Environmental Science and Engineering, Donghua University, Shanghai 201620, China \\ ${ }^{2}$ Xinhua Hospital Affiliated to Medical College of Shanghai Jiaotong University, Shanghai 200092, China
}

\begin{abstract}
Paroxysmal fumes during surgical operations endanger the health of medical staff. Special measures for removing surgical smoke are lacking. Article Real-time monitoring of particulate matter concentrations in surgical smoke at different locations under different surgical conditions were explored, and a particulate matter purification control strategy was proposed. The $\mathrm{PM}_{2.5}$ and $\mathrm{PM}_{10}$ concentrations in the operating and respiratory zones near the operating table were about 3.0 times more than the specified value, but both surgical procedures met the requirements of PM concentration in the public zone. Therefore, a clean operating room is not clean for medical staff. The smoke produced by the three scalpels resulted in particle

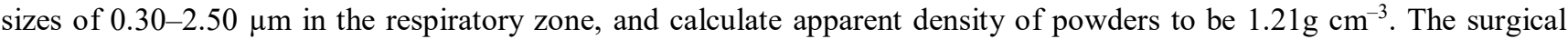
smoke produced by the ultrasound scalpel resulted in the highest median $\mathrm{PM}_{10}$ concentration in the operating area. The results show that the smoke produced by different surgical conditions is mainly ultra-fine particles, which are more likely to harm the health of medical staff. A small surgical smoke circulation purification and dust removal system was designed, which could effectively suppress the spread of surgical smoke and reduce the occupational hazards of medical staff. The optimized control plan could significantly reduce the $\mathrm{PM}_{2.5}$ concentration value at measurement point a when the electric knife was turned on by approximately $200.0 \%$. The $\mathrm{PM}_{2.5}$ concentration of breathing zone was close to $75.0 \mu \mathrm{g} \mathrm{m}{ }^{-3}$, which basically met the occupational health requirements. The decrease in the $\mathrm{PM}_{2.5}$ concentration of operating zone was about $50.0 \%$, but it still exceeded the limit. It had a reference value for the occupational health protection of the first-line medical staff of existing epidemics.
\end{abstract}

Keywords: Surgical smoke; Fine particles; Distribution characteristics; Control strategy.

\section{INTRODUCTION}

Air quality and environmental issues that affect human health have created widespread concern, resulting in research on environmental particulate pollution control by the government and scholars. As a typical highly clean indoor space in Fig. 1(A), surgical operating rooms face the intrusion of different pollutants, such as medical gases, cell debris, and aerosols, which severely endanger the health of patients and medical staff (Bree et al., 2017; Lee et al., 2018). With the development of surgical techniques and the widespread use of equipment, surgical smoke as a typical source of pollution poses a significant hazard in surgical environments (Wang et al., 2016; Buonanno et al., 2019).

\footnotetext{
* Corresponding author.

Tel.: 13818883351

E-mail address: shenhg@126.com
}

\section{Surgical Smoke as Primary Pollution Source}

Surgical smoke contains fine particles caused by the destruction, ablation, and decomposition of tissue when a high-frequency electrosurgical knife, laser knife, or ultrasonic scalpel is used, as shown in Fig. 1(C). It is an aerosol that consists of $95 \%$ water and 5\% granulated cell debris (Baier et al., 2019). Studies have shown that a large number of harmful chemical components in surgical smoke, such as hydrocarbons, nitriles, organic amines, aldehydes and a small amount of hydrogen cyanide, formaldehyde, benzene, DNA (Moot et al., 2007). According to statistics from the Occupational Safety and Health Administration, about 500,000 people are exposed to surgical smoke annually, including nurses, anesthesiologists, surgeons, and patients (Watson, 2010). Headaches and inflammation of the eyes and mucous membranes are common symptoms among operating room personnel, who also face an increased risk of developing cancer from long-term exposure (Barret and Garber, 2003; Peng et al., 2019). The type of surgery and scalpel and the pathology of the target tissue significantly influence the characteristics of paroxysmal particulate pollutants during an operation (Kanter, 1992; Wu et al., 2011). 


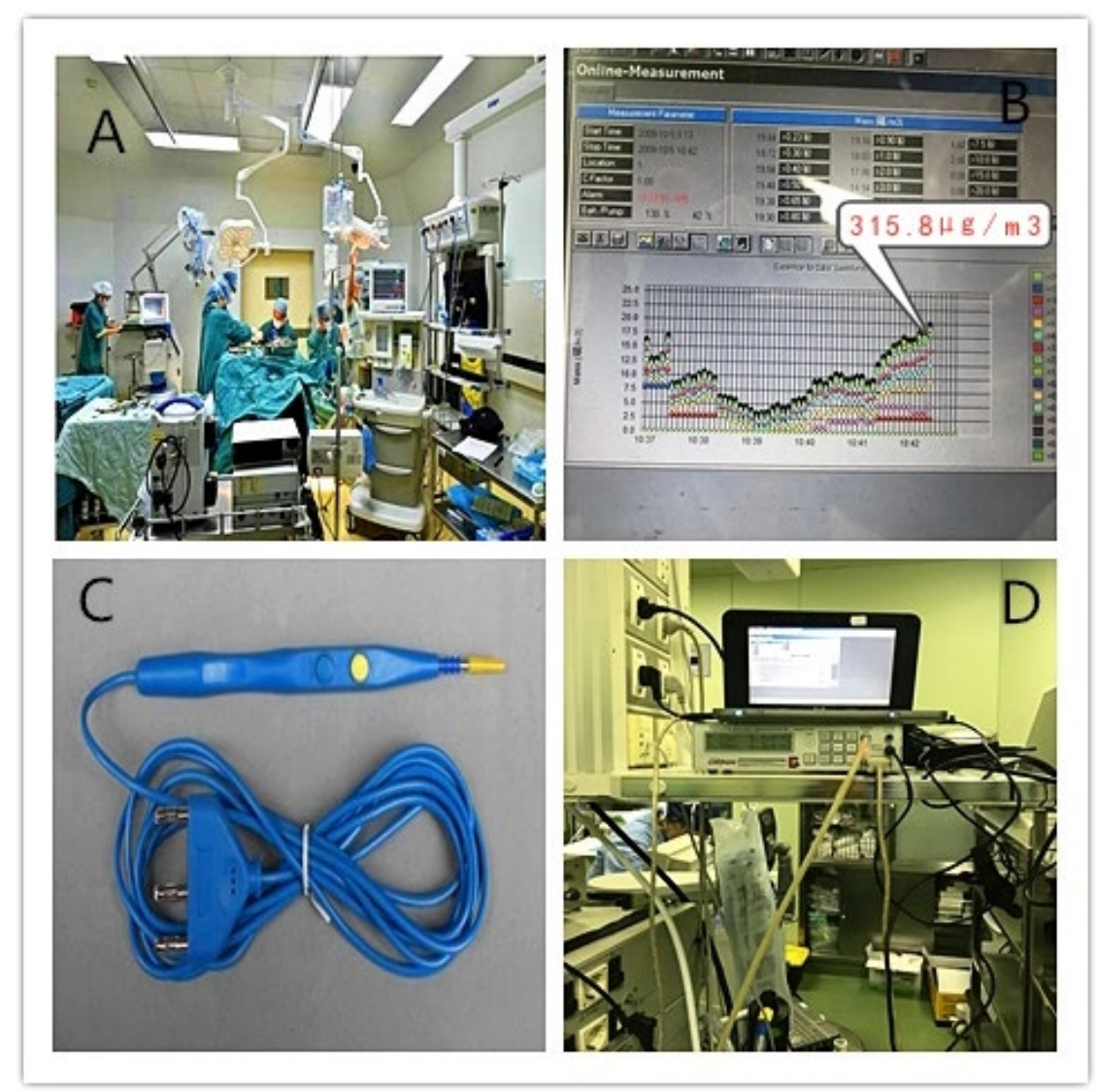

Fig. 1. Background image of surgery.

As the human body is exposed to fine particulate matter, the concentration mainly determines the amounts of fine particles of different sizes that directly invade the human respiratory tract, depositing in the lungs (Whyte et al., 2019). Since 2008, the National Institute of Occupational Safety and Health (NIOSH) and the American Association of Operating Room Nurses (AORN) have sought to prevent operating room smoke by introducing management countermeasures and practices.

\section{Airborne Particles as Main Component of Surgical Smoke}

The level of exposure to fine particles is closely related to human health. Airborne particles in surgical smoke can cause various ailments and diseases, such as headaches, retching, inflammation, and cancer (Kwak et al., 2016; Wang et al., 2019). When using resection or electrocoagulation during surgery, a large quantity of respirable particles can be generated, and $95 \%$ of the particles have particle sizes between $0.3 \mu \mathrm{m}$ and $5.0 \mu \mathrm{m}$ (Li et al., 2013). The concentration of aerosol particles near the nose of medical staff can be as high as $3.6 \times 10^{8} \mathrm{~m}^{-3}$ (Zoon et al., 2011). Studies have shown that different surgical procedures and types of surgical scalpels can cause different concentrations of particulate matter during surgery. For example, the concentration of surgical smoke particles from a short-term, high-frequency electrosurgical knife can reach 60,000-100,000 $\mathrm{m}^{-3}$ in 5 min. Laser scalpels produce approximately twice the concentration of particulate matter in smoke (Imani et al., 2018; Kuga et al., 2018). There are significant differences between superficial and abdominal surgeries, which produce $\mathrm{PM}_{2.5}$ concentrations of 245.7 and $149.4 \mu \mathrm{g} \mathrm{m}^{-3}$ after 3-6 s of electrosurgical opening, respectively (Chen et al., 2018; Golda et al., 2019). However, previous research has not focused on the monitoring and hazard analysis of the particle concentration of surgical smoke near the medical staff during different surgical procedures using different knives.

\section{Clean Operating Room May Not be "Clean"}

Operating rooms should be absolutely sterile and clean spaces, equipped with independent constant temperature and humidity clean air-conditioning systems and disinfection measures. On the one hand, these systems prevent infections from surgical sites due to the presence of pollutants from medical devices, medical staff, and the surrounding environment (Chavis et al., 2016). On the other hand, ensuring that medical personnel perform operations in a clean and comfortable environment can help improve the probability of a successful aseptic surgery (In et al., 2015). At present, operating room design and safeguard measures ensure the clean requirements of the operating environment as much as possible. People believe that operating rooms should be absolutely clean spaces, but one study showed that $85.0 \%$ of the interviewed medical staff agreed that the operating room was absolutely clean (Pennock, 2020). However, some studies have shown that there were more than 600 chemical 
components in surgical smoke (Carbajo-Rodriguez et al., 2009). The average daily smoke produced by an operating room was equivalent to the smoke produced by the burning of 27 to 30 cigarettes (Okoshi et al., 2015). There is a direct relationship between the number of Chinese medical staff, the number of patients with postoperative infections, and the smoke during the operation (Mellor and Hutchinson, 2013). Summarizing the existing research from recent years, the main reasons for the contamination of clean operating rooms are as follows. (1) Medical staff entering and exiting during the operation cause the airtight door of the operating room to open, allowing bacteria to enter and endangering human health (Huang et al., 2019). (2) The long-term failure of purification devices of the existing clean ventilation systems creates pollution in the surgical environment (Bigony, 2007). The different surgical smoke jets under the action of scalpels that medical staff inhale are often ignored. However, ordinary surgical masks can only filter particles larger than $5 \mu \mathrm{m}$. Even if the medical staff wear protective masks, fine particles can still be inhaled. The existing clean ventilation technology is designed for the overall purification of operating rooms, and there has been no substantial research on how to capture and purify surgical smoke efficiently. Therefore, a clean operating room might not be "clean" for medical staff and patients in Fig. 1(B).

\section{MATERIALS AND METHODS}

In this study, the concentration of particulate matter in an operating room was measured in real time for different scalpels and surgical operations in Fig. 1(D), and the concentration of particulate matter of different sizes at the moment of scalpel opening was analyzed. Based on the test results, a small-scale circulating purification and dust removal system was proposed to reduce the PM concentration in the doctor's breathing zone.

\section{Experimental Design}

This experiment was based on a 100-level laminar flow clean operating room $(\mathrm{L} \times \mathrm{W} \times \mathrm{H}=6.3 \mathrm{~m} \times 5.1 \mathrm{~m} \times 3.0 \mathrm{~m}$ $\left.=96.4 \mathrm{~m}^{3}\right)$. The operating room was equipped with a highefficiency, independent temperature and humidity controlling displacement ventilation and purification system, where the purification level was $\mathrm{H} \mathrm{14}$, and the purification efficiency of fine particulate matter reached $99.995 \%$ (Yau and Ding, 2014). The results of the public environmental measurements met the requirements of Chinese operating room regulations, as described in Section 3.1 and 3.2(GB3095, 2012). The air supply port was in the middle of the ceiling $(2.6 \mathrm{~m} \times 2.4 \mathrm{~m})$. Each side wall was arranged with a louver air return outlet $(4.8 \mathrm{~m} \times 0.8 \mathrm{~m})$ from the ground $(0.1 \mathrm{~m})$. The operating table was located in the middle of the room $(1.8 \mathrm{~m} \times 0.6 \mathrm{~m} \times 0.8 \mathrm{~m})$. Without consideration of the operating procedure, according to the GB/T 16292-2010 standard (Test method for suspended particles in clean rooms (areas) of the pharmaceutical industry), the concentrations of particulate matter at measurement point a (0.8-1.2 $\mathrm{m}$ from the ground), point $\mathrm{b}(1.5-1.7 \mathrm{~m}$ from the ground), and environmental area point c $(2.0 \mathrm{~m}$ away from the operating table) outside the operating table were monitored during the operation. Fig. 2 shows the arrangement of the measurement points.

\section{Experimental Pilot and Instrument}

The operating room temperature, relative humidity, and operation time were $24.6 \pm 1.3^{\circ} \mathrm{C}, 46.7 \pm 1.2 \%$, and $2.5 \mathrm{~h}$, respectively. The whole test process was synchronized with the doctor's operation time, and the test times for all the instruments were synchronized to eliminate experimental errors caused by experimental asynchronous testing. Experimental studies had shown that there were obvious differences in the doses of surgical smoke produced by different parts of human surgery (Su et al., 2019). According to interviews with front-line medical staff, the surgical smoke generated during prostate and thyroid cancer resection

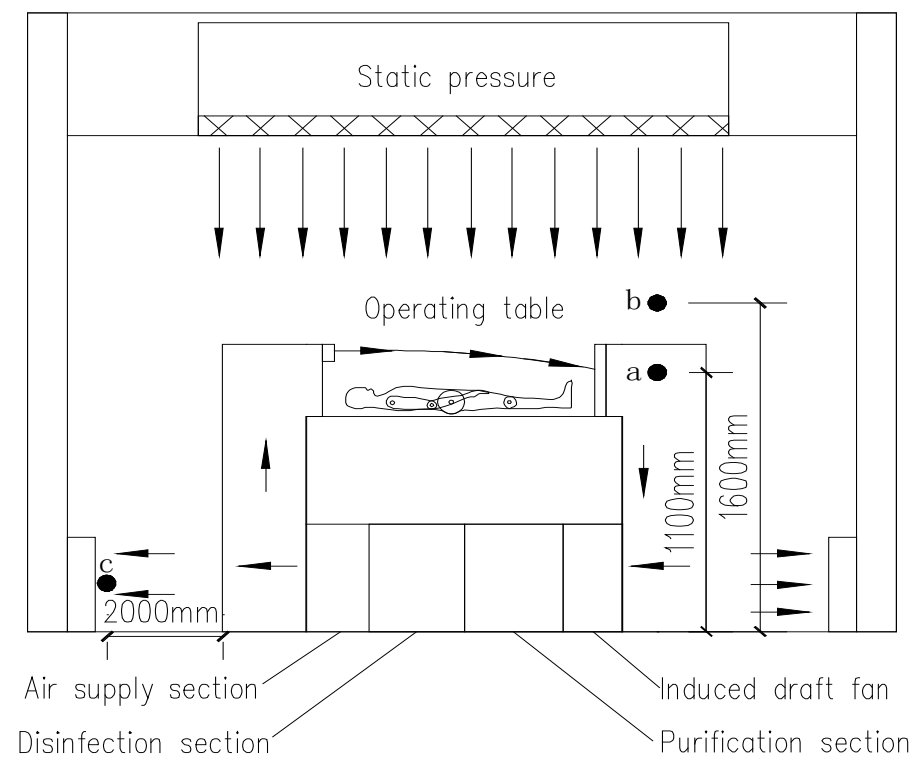

Fig. 2. Layout of measurement points for instruments in the clean surgical operating room. 
was the most irritating to the human body. In response to the needs of on-site medical staff, the article repeatedly monitored multiple thyroid surgery and prostate cancer surgery cancer at the same time, and took the average value of PM as an explanation. In view of the high degree of purification of the pre-operative environment, the effect of the PM concentration on the experiment environment was ignored. To avoid hindering the doctor's operation, portable dust testing instruments were used in all the experiments. Portable aerosol optical particle size spectrometer probes from the Grimm Company of Germany were set up at measurement points $\mathrm{a}$ and $\mathrm{b}$, and the instrument model was a Grimm 1.108, which recorded data every $0.6 \mathrm{~s}$ on average. The range of particulate matter tested was $0.30-20 \mu \mathrm{m}$. A portable atmospheric dust monitor from TSI Incorporated (model TSI8530, United States) was set up at point c, and the range of particulate matter tested was $0.10-10 \mu \mathrm{m}$. Table 1 shows the specific parameters of the test instruments. To avoid interference with the operating procedures of the medical staff, all probes were fixed on medical equipment at a certain height near the operating table. There was not a significant difference in the risk of exposure in the same surgical environment between members of the same medical team (Ragde et al., 2016). According to the GB3095-2012 "Ambient Air Quality Standard," an average $\mathrm{PM}_{2.5}$ concentration of $<35.00 \mu \mathrm{g} \mathrm{m}^{-3}$ meets the requirements for air cleanliness, and an average $\mathrm{PM}_{2.5}$ concentration of $<75.00 \mu \mathrm{g} \mathrm{m}^{-3}$ meets the health requirements for personnel.

\section{Experiment Content and Control Strategy}

The operating room of a hospital in Shanghai was used as the test object to monitor the concentration of particulate matter in the concentration area of the medical staff and the public environment area under different operating conditions. The main features were as follows. (1) Measurement points were set in the public environment areas in the operation zone, respiratory zone, and public environment zone. The concentrations of fine particulate matter in different locations of the operating room during two different operations (prostate and thyroid cancer resection) and three different scalpels (electric scalpel, laser scalpel, and ultrasound scalpel) were obtained by synchronized measurements. A double sample t-test (significance level $\mathrm{P}<0.05$ ) was used to test the results, which provided a reliable basis for future research on the monitoring and control technology of clean surgical environments. (2) A small surgical smoke circulation purification system was designed. The operating principle is shown in Fig. 3(A). A group of combined ultra-quiet purification units was arranged at the bottom of the operation bed, a long strip air supply port was arranged above the head of the patient, and a smoke exhaust port was arranged at the foot area. When the doctor performed the operation, the air supply section blew clean fresh air from the air supply port and blew the surgical smoke to the smoke exhaust port. The air exhaust port drew in the surgical smoke and sent it to the purification and disinfection sections to process the polluted air stream to satisfy the GB50333-2013 "Building Technical Specification for Clean Surgery Department of the Hospital" standard for recycling, forming an air curtain layer above the operating table. This provided the fastest isolation and suction of surgical smoke, preventing the smoke from escaping to the environment, as shown in Fig. 3(B). (3) The particle concentrations of the doctor's respiratory zone were compared and analyzed under conventional surgical purification conditions to evaluate the protective effect of the small surgical smoke circulation purification system. The framework for determining the effect of the surgical smoke concentration factors and control strategy are shown in Fig. 4.

\section{RESULTS AND DISCUSSION}

\section{Different Types of Surgical Procedures}

The time-dependent characteristics of the particulate matter concentration at different measurement points during two different operations with the same scalpel were tested, and the test results are shown in Fig. 5. The statistical results showed that the concentrations of a, b, c paroxysmal particles in the three sites of the prostate cancer surgery were higher than those of the thyroid cancer surgery. Therefore, the particle concentrations of different types of surgical smoke can differ significantly. The mean value of the concentration at measurement points $a$ and $b$ exceeded the limit by about $400.0 \%$. The particulate matter at measurement point a was mainly $\mathrm{PM}_{2.5}$. Measurement point $\mathrm{b}$ contained coarse $\mathrm{PM}_{10}$ particles. The concentrations of the two surgical smokes at measurement point $\mathrm{c}$ met the environmental requirements.

Figs. 5(A) and 5(B) show the $\mathrm{PM}_{2.5}$ and $\mathrm{PM}_{10}$ distribution changes for measurement point a during the prostate cancer surgery and thyroid cancer surgery, respectively. There were significant differences in the concentrations of $\mathrm{PM}_{2.5}$ and $\mathrm{PM}_{10}$ between the two surgical smog types in the doctors' respiratory zone, and there was a significant difference between the two concentrations (all $\mathrm{P}<0.001$ ). Especially when the scalpel is turned on, the concentration of $\mathrm{PM}_{2.5}$ reached approximately $425.63 \mu \mathrm{g} \mathrm{m}^{-3}$ and $812.34 \mu \mathrm{g} \mathrm{m}^{-3}$, which indicated serious pollution, when regardless of the other affecting components of air quality. The ratio of $\mathrm{PM}_{10} / \mathrm{PM}_{2.5}$ was found to be close to one, the particulates in the surgical smoke were almost all $\mathrm{PM}_{2.5}$ (Baier et al., 2019). The $\mathrm{PM}_{2.5}$ was surgical smoke is concentrated in the respiratory zone

Table 1. Test instrument parameter table.

\begin{tabular}{|c|c|c|c|c|c|c|}
\hline Item & Name of instrument & Brand model & $\begin{array}{l}\text { Number of } \\
\text { instruments }\end{array}$ & Accuracy & Test range $\left(\mu \mathrm{g} \mathrm{m}^{-3}\right)$ & $\begin{array}{l}\text { Particle size } \\
\text { range }(\mu \mathrm{m})\end{array}$ \\
\hline 1 & $\begin{array}{l}\text { Portable aerosol optical } \\
\text { particle size spectrometer }\end{array}$ & Grimm1.108 & 2 & $\pm 2 \%$ & $1.0 \times 10^{-1}-1.0 \times 10^{5}$ & $0.30-20$ \\
\hline 2 & Atmospheric dust monitor & TSI8530 & 1 & $\pm 5 \%$ & $1.0 \times 10^{-3}-4.0 \times 10^{5}$ & $0.10-10$ \\
\hline
\end{tabular}




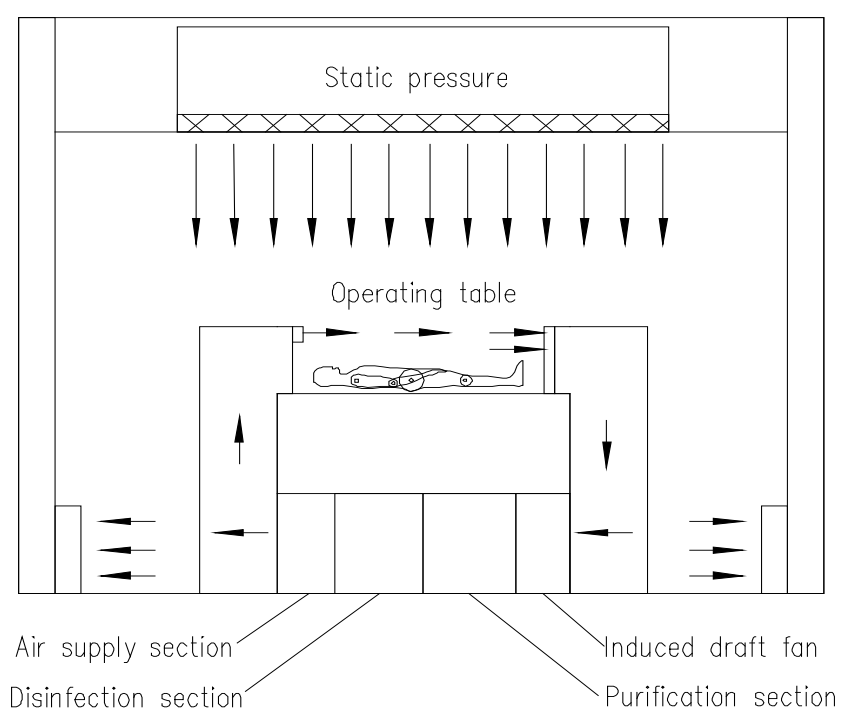

(A)

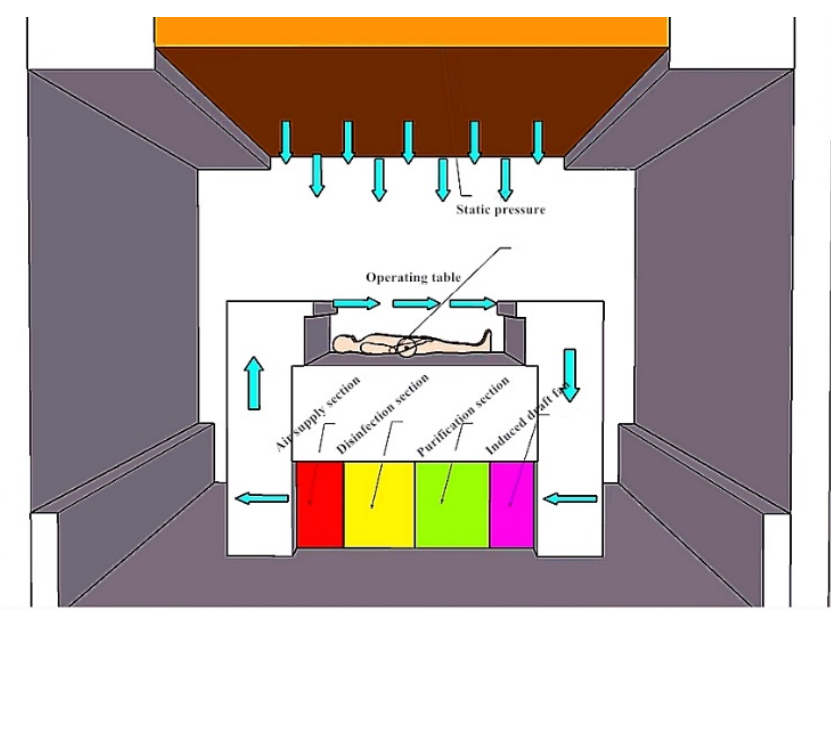

(B)

Fig. 3. (A) Plan and (B) elevation of the small surgical smoke circulation purification system.

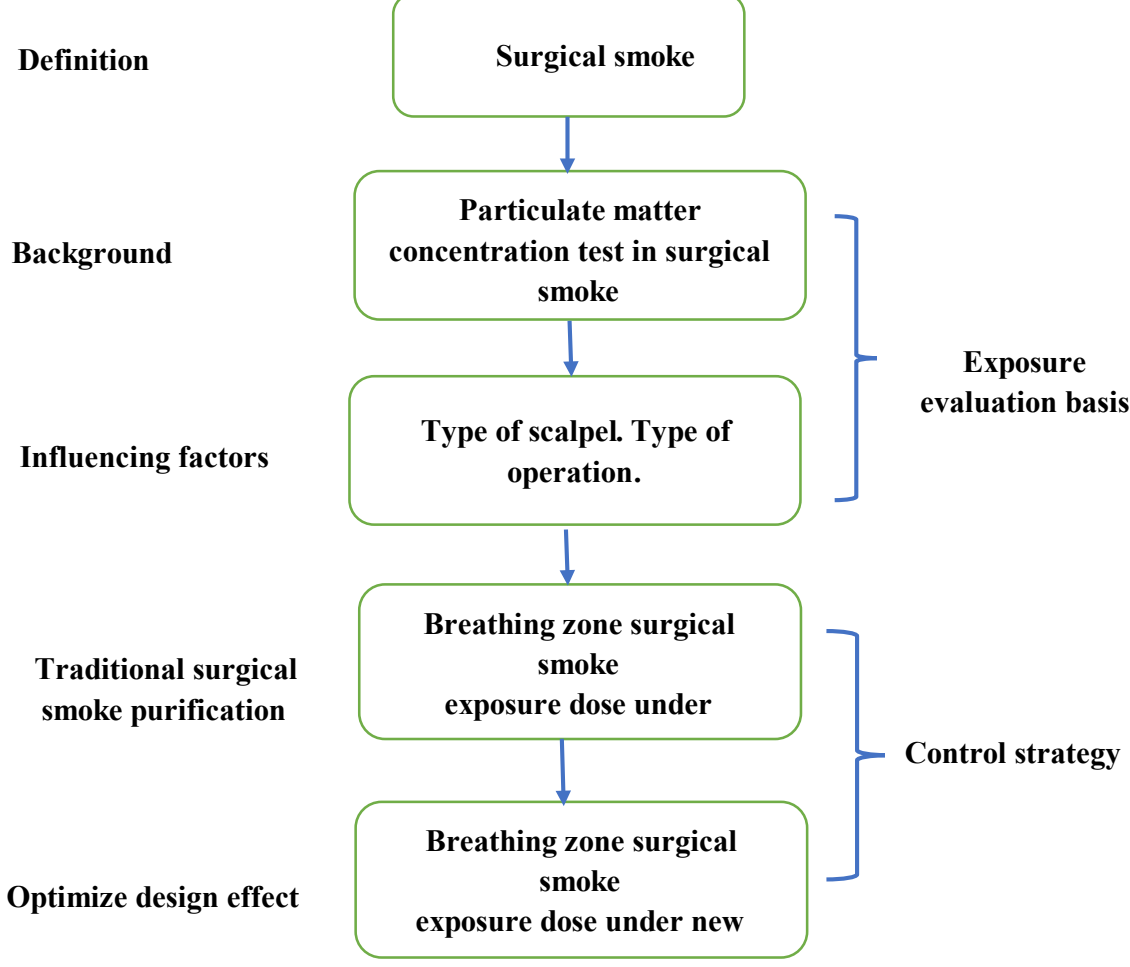

Fig. 4. Framework for effect of surgical smoke concentration factors and control strategy.

of the medical staff under the influence of the hot plume. This indicated that the delivery of clean air was affected at the top of the operating room. This caused a sharp increase in the concentration of $\mathrm{PM}_{2.5}$ at measurement point $\mathrm{a}$, which dropped rapidly. Such incidents result in medical personnel immediately inhaling particles to the alveoli, which is harmful to their health (Fan et al., 2019). Therefore, it was obvious differences that the concentration of PM produced by cutting different tissue cells during the operation.

Figs. 5(C) and 5(D) show the $\mathrm{PM}_{2.5}$ and $\mathrm{PM}_{10}$ distribution changes for measurement point $\mathrm{b}$ during prostate and thyroid cancer surgeries, respectively. The peak times of $\mathrm{PM}_{2.5}$ and $\mathrm{PM}_{10}$ increased, and their fluctuations were large (all $\mathrm{P}$ $<0.001$ ). The ratio of $\mathrm{PM}_{10} / \mathrm{PM}_{2.5}$ was stable at values greater than one, indicating that the operating area mainly contained $\mathrm{PM}_{10}$ particles. There was a large amount of cell debris in the paroxysmal particles in the local area of the surgical site, possibly due to its proximity to the knife edge (Heinsohn et al., 1991). Every time the scalpel was turned on, the PM concentration increased sharply. The peak value was close 
to $800.0 \mu \mathrm{g} \mathrm{m}^{-3}$, which was approximately $6-8$ times higher than the normal value. Those measuring 0.5 to $10.0 \mu \mathrm{m}$ were considered as "powder harmful to the lung" because it could penetrate in its deepest areas. However, medical staff members in the operating room and administrators ignored the hazards of surgical smoke.

Figs. 5(E) and 5(F) show the $\mathrm{PM}_{2.5}$ and $\mathrm{PM}_{10}$ distribution changes for measurement point $\mathrm{c}$ during the prostate and thyroid cancer surgeries, respectively. The $\mathrm{PM}_{2.5}$ concentration in the area outside the operating table during the operation was less than $35.00 \mu \mathrm{g} \mathrm{m}^{-3}$, indicating that the fine particle
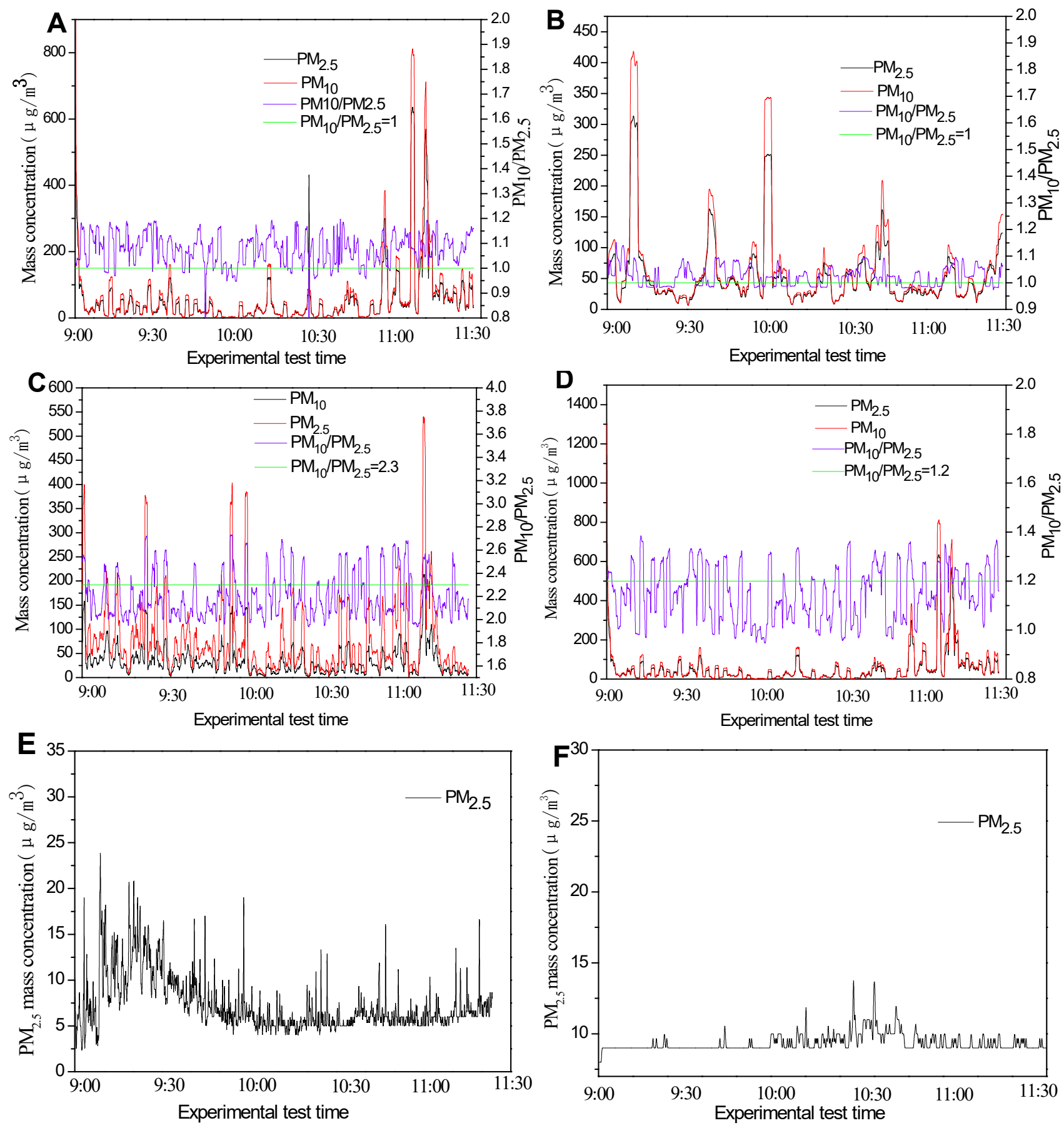

Fig. 5. Mass concentrations of paroxysmal fine particles in different kinds of surgical procedures. concentration in the public area outside the operating table met the requirements for the clean environment control

\section{Different Surgical Scalpels}

To explore the effect of scalpel type on the characteristics of paroxysmal particulate matter during an operation, the surgical test environment was kept the same. The measurement time was 13:00-15:30. Fig. 6 shows the statistical analyses of the $\mathrm{PM}_{2.5}$ and $\mathrm{PM}_{10}$ concentrations of surgical paroxysmal particulate matter for three kinds of scalpels (electric, laser, during the operation. 
and ultrasound). There were significant differences in the particle concentrations and sizes of the surgical smoke generated by the three scalpels cutting human tissue. The mean values of the concentration of the surgical smoke generated by the electric knife at measurement points a and $\mathrm{b}$ were the largest. The surgical smoke produced by the three scalpels mainly contained fine particles in the range of 0.3
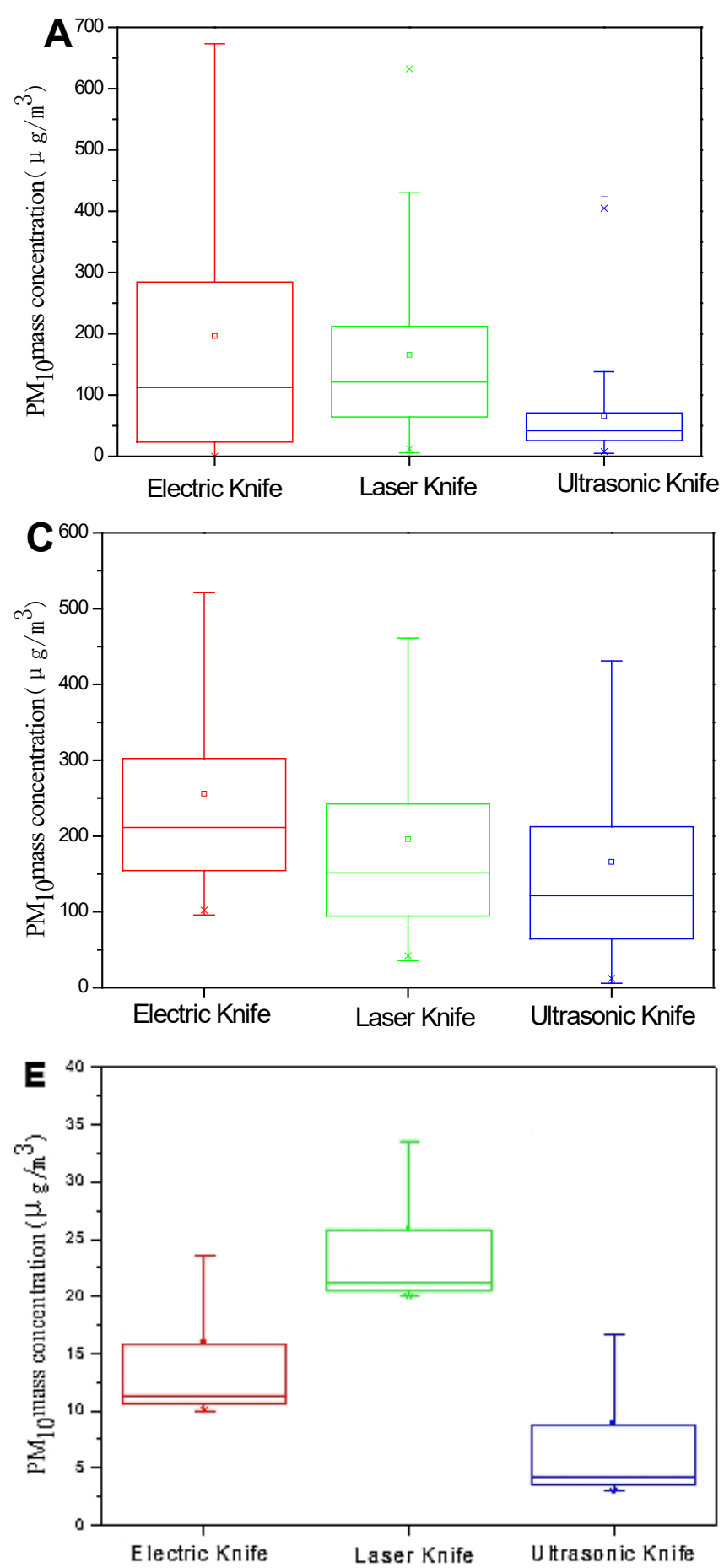

$2.5 \mu \mathrm{m}$, which can cause headaches and inflammation of the eyes and mucous membranes among medical staff members in the operating room (Mosonik et al., 2018). For the three types of scalpels cutting human tissue, the mean value of the particle concentration at measurement point $\mathrm{c}$ met the requirements for environmental control.

Figs. 6(A) and 6(B) show the mass concentrations of
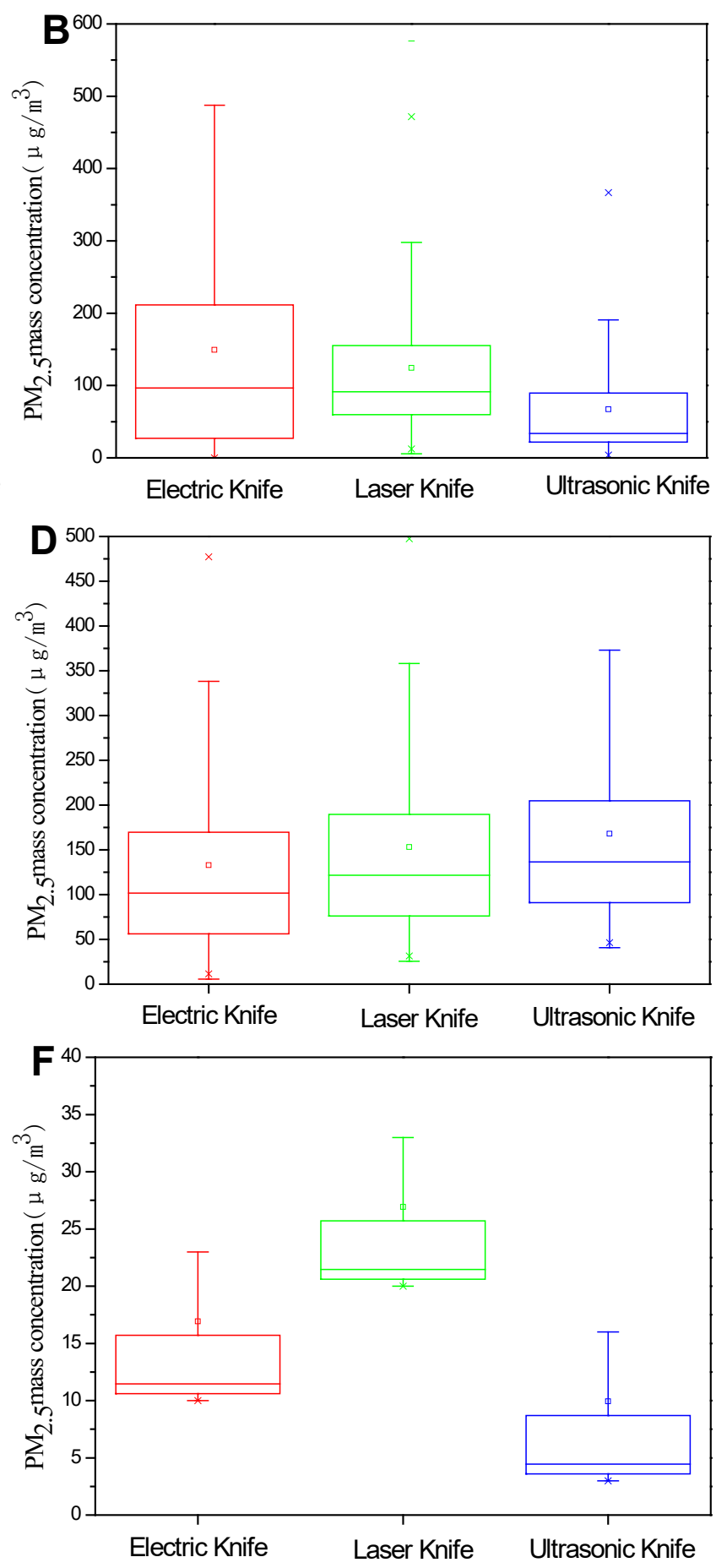

Fig. 6. Box plots of paroxysmal fine particulate mass concentrations induced by different scalpels. The box plots show 5 th and 95th percentiles, $1 \mathrm{st}\left(Q_{1}\right)$ and 3rd $\left(Q_{3}\right)$ quartiles, and median value of the ratios. Upper (U) and lower (L) whiskers were evaluated as $U=Q_{3}+1.5 \times\left(Q_{3}-Q_{1}\right)$ and $L=Q_{1}-1.5 \times\left(Q_{3}-Q_{1}\right)$, respectively. Measurement data higher than the "upper whisker" or lower than the "lower whisker" were considered to be outliers and are not shown here. 
$\mathrm{PM}_{10}$ and $\mathrm{PM}_{2.5}$ at measurement point a, respectively, with box diagrams. The median mass concentrations of $\mathrm{PM}_{10}$ at point a were $116.4,121.2$, and $43.23 \mu \mathrm{g} \mathrm{m}^{-3}$ for electric, laser, and ultrasound scalpel operations, respectively. However, from the length of the box, the box of the electrosurgical operation was significantly longer, indicating that the fluctuation of the particle concentration during the electrosurgical surgery operation was highly volatile in Fig. 6(A). The median values of $\mathrm{PM}_{2.5}$ were $102.1,96.23$, and $36.83 \mu \mathrm{g} \mathrm{m}^{-3}$, for electric, laser, and ultrasound operations, respectively in Fig. 6(B). The main component of the suspended particles in the operating smoke produced by the three kinds of scalpels at the upper part of the operating table was $\mathrm{PM}_{2.5}$ (Bae et al., 2018).

Figs. 6(C) and 6(D) show box diagrams of the mass concentrations of $\mathrm{PM}_{10}$ and $\mathrm{PM}_{2.5}$, respectively, at measurement point $b$. The median values of $\mathrm{PM}_{10}$ at point $b$ were $223.2,148.6$, and $124.3 \mu \mathrm{g} \mathrm{m}^{-3}$ for the electric, laser, and ultrasound scalpel operations, respectively in Fig. 6(C). The median mass concentrations of $\mathrm{PM}_{2.5}$ were 102.4, 141.5, and $172.2 \mu \mathrm{g} \mathrm{m}^{-3}$ in Fig. 6(D), and the corresponding values of $\mathrm{PM}_{10}$ and $\mathrm{PM}_{2.5}$ were almost equal. These results revealed that the total weight concentration of fine particulate matter in the operating area was close to that of the smoke generated by the three scalpels.

Figs. 6(E) and 6(F) show the mass concentrations of $\mathrm{PM}_{10}$ and $\mathrm{PM}_{2.5}$, respectively, at measurement point $\mathrm{c}$. The mass concentrations of $\mathrm{PM}_{10}$ and $\mathrm{PM}_{2.5}$ in the indoor public environment during the operations using the three scalpels were not more than $30.00 \mu \mathrm{g} \mathrm{m}^{-3}$, which were much smaller than the concentration of fine particles near the operating table. The concentration of suspended fine particulate matter in the operating and respiratory areas near the operating table exceeded the standard during the operation, which would significantly endanger the occupational health of the medical staff (Stocks et al., 2010; Mentese and Tasdibi, 2016). However, the concentration of the indoor public environment area met the requirements for clean control, and the main component was $\mathrm{PM}_{2.5}$.

The fine particles in the surgical plume carry viral genes or carcinogens suspended in the respiratory areas of the medical staff due to thermal buoyancy during the operation of the scalpel, which directly endangers the health of the medical staff (Ziegler et al., 1998). The peak mass concentrations of fine particulate matter $500 \mathrm{~s}$ before and after the opening by the three scalpels were analyzed: L (laser scalpel), E (electric scalpel), and F (ultrasonic scalpel), as shown in Fig. 7(A).

The total mass concentration $\left(326.8 \mu \mathrm{g} \mathrm{m}^{-3}\right)$ of fine particles produced by the electric knife was significantly higher than that of the other two scalpels. Analogously, the total mass concentration of fine particles produced by the laser scalpel $\left(262.4 \mu^{-3} \mathrm{~g} \mathrm{~m}^{-3}\right)$ was similar to that produced by the ultrasonic scalpel $\left(251.3 \mu \mathrm{g} \mathrm{m}^{-3}\right)$. The particle size of lung-damaging dust was generally $0.5-5 \mu \mathrm{m}$, which can cause severe lung injuries, such as bronchitis and asthma (Ziegler et al., 1998). The results reveal that the average particle sizes of the smoke generated by the electric, laser, and ultrasonic scalpels were $0.07,0.317$, and 0.35-6.5 $\mu \mathrm{m}$, respectively (Bensaha, 2013; Yau and Ding, 2015; Applewhite et al., 2017).

Fig. 7(B) shows that the surgical smoke produced by the three scalpels mainly contained fine particles in the range of $0.3-2.5 \mu \mathrm{m}$. The particle size was lower than that of the lung-damaging dust. The concentration of fine particles produced by the electrosurgical knife was also significantly higher than that of the other two types of scalpels, endangering the health of the medical personnel.

\section{Control Strategies to Prevent Doctors' Exposure to Surgical Smoke}

High-efficiency purification of clean room particles could effectively prevent post-operative infections and protect the health of the medical staff. From the analysis of the test data in this paper, the purification system of the traditional clean operating room could only meet the control standard of the concentration of the public environment. For the particles close to the operation area of the operating table (near the patient) and the respiratory zone (near the medical staff) during the operation opening time, the concentrations were much greater than the clean operating room control requirements (Bensaha, 2013; Zahir et al., 2018). Traditional clean operating room ventilation system purification could not guarantee the health of surgical patients and medical
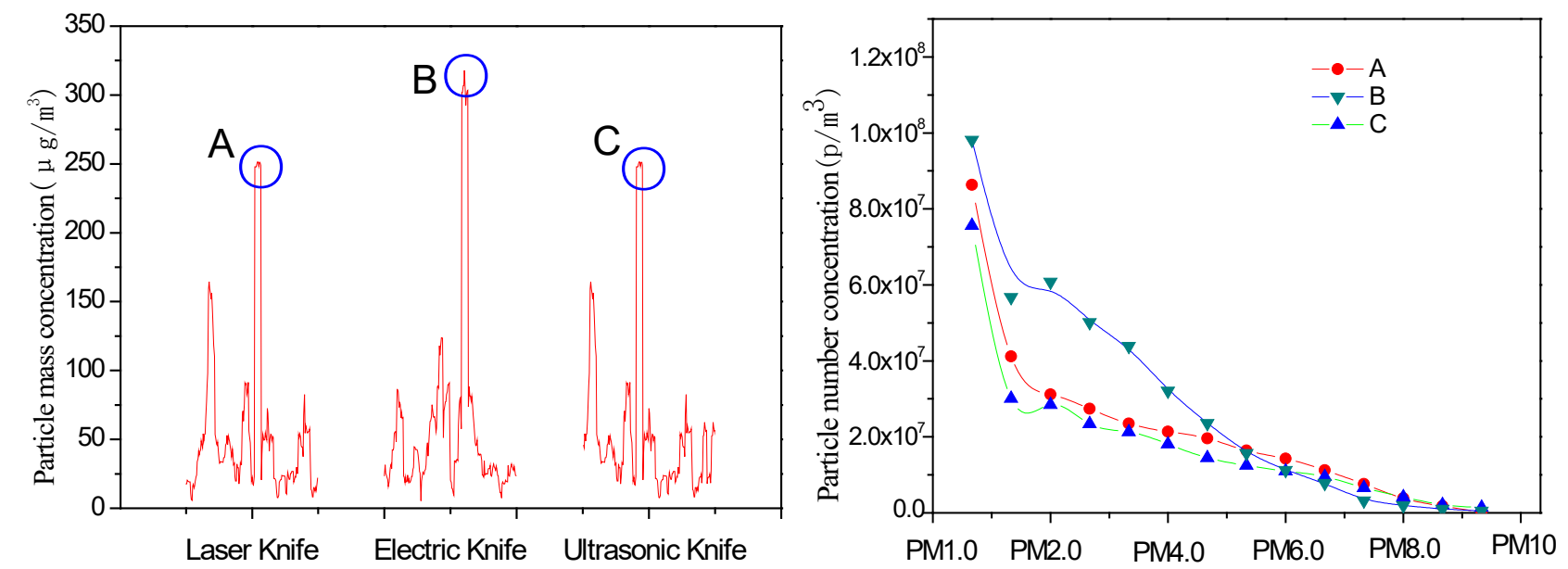

Fig. 7. Peak mass concentration of fine particulate matter $500 \mathrm{~s}$ before and after the opening by the three scalpels. 
staff. The small-scale circulating purification and dust removal system was designed to form an air curtain above the operating bed to prevent the operation smoke from being emitted to the surrounding environment (the doctor's respiratory zone) and to capture the surgical smoke particles as quickly as possible (Nikaeen et al., 2018; Wu et al., 2019). According to the previous results, the same type of surgery using an electric knife was analyzed, ignoring other external interference factors (such as the operation door opening and medical staff motion). Two operating plans were designed for the ventilation and purification system in the operating room. Plan 1: The operating room was only equipped with a large replacement ventilation system. The small and medium circulation purification system in Fig. 2 was closed, and the $\mathrm{PM}_{2.5}$ mass concentrations at measurement points $\mathrm{b}$ and $\mathrm{c}$ were measured within $500 \mathrm{~s}$ of the electric knife being turned on. Plan 2: The operating room was equipped with a large displacement ventilation system and the small and medium circulation purification systems shown in Fig. 2. The $\mathrm{PM}_{2.5}$ mass concentrations at measurement points $\mathrm{b}$ and $\mathrm{c}$ were measured within $500 \mathrm{~s}$ of the electric knife being turned on. Finally, the $\mathrm{PM}_{2.5}$ mass concentration values at measurement points $\mathrm{b}$ and $\mathrm{c}$ of the two operating strategies were compared and analyzed, as shown in Fig. 8. Compared with plan 1, plan 2 significantly reduced the $\mathrm{PM}_{2.5}$ concentration at measurement point a (breathing zone) when the electric knife was turned on. The average reduction was about $200.0 \%$, and the $\mathrm{PM}_{2.5}$ concentration was close to $75 \mu \mathrm{g} \mathrm{m}^{-3}$ in Fig. 8(A). This basically met the ambient air requirements for the personnel occupational health. Thus, the use of small and medium circulation purification systems could prevent the exposure hazards of surgical medical staff to surgical smoke. For measurement point $b$ (operation zone), plan 2 could also reduce the $\mathrm{PM}_{2.5}$ value significantly compared to plan 1 , by about $50.0 \%$. However, the $\mathrm{PM}_{2.5}$ concentration values were $>75 \mu \mathrm{g} \mathrm{m}^{-3}$ in Fig. 8(B), indicating that fine particles in this area still exceeded the standard. This may have been because the rising smoke during the operation was blocked by the air curtain at the top. Thus, some fine particles were not drawn in and purified in time, escaping to both sides. There was a possibility of further escape to other areas of the environment. Barrier measures were set on both sides to prevent the further dispersal of fine particles in the surgical smoke.

\section{CONCLUSION}

Paroxysmal fine particulate matter released during surgical procedures endangers the health of medical personnel in operating rooms. The real-time variations of the concentration of fine particulate matter in a confined clean laboratory under different operating conditions were studied. Based on the results, a small surgical smoke circulation purification and dust removal system was designed, and the $\mathrm{PM}_{2.5}$ concentration values at measurement points $\mathrm{a}$ and $\mathrm{b}$ under the two control plans were compared and analyzed. The main conclusions were as follows. (1) The particle concentration of different types of surgical smoke were significantly different. The mean value of the concentrations at measurement points $\mathrm{a}$ and $\mathrm{b}$ exceeded the limit by about $400.0 \%$. The particulate matter at measurement point a was mainly $\mathrm{PM}_{2.5}$. Measurement point $\mathrm{b}$ contained coarse $\mathrm{PM}_{10}$ particles. The concentrations of the two surgical smokes at measurement point $\mathrm{c}$ met the environmental requirements. (2) There were significant differences in the particle concentrations and sizes in the surgical smoke generated by the three types of scalpels cutting human tissue. The mean values of the concentration of surgical smoke generated by the electric knife at measurement points $a$ and $b$ were the largest, the surgical smoke produced by the three scalpels mainly contained fine particles in the range of $0.3-2.5 \mu \mathrm{m}$, which is the most harmful to the occupational health of the surgical medical staff. Using the three types of scalpels to cut human tissue, the mean value of the particle concentration at measurement point $\mathrm{c}$ met the requirements for environmental control. (3) Compared with plan 1, plan 2 could significantly

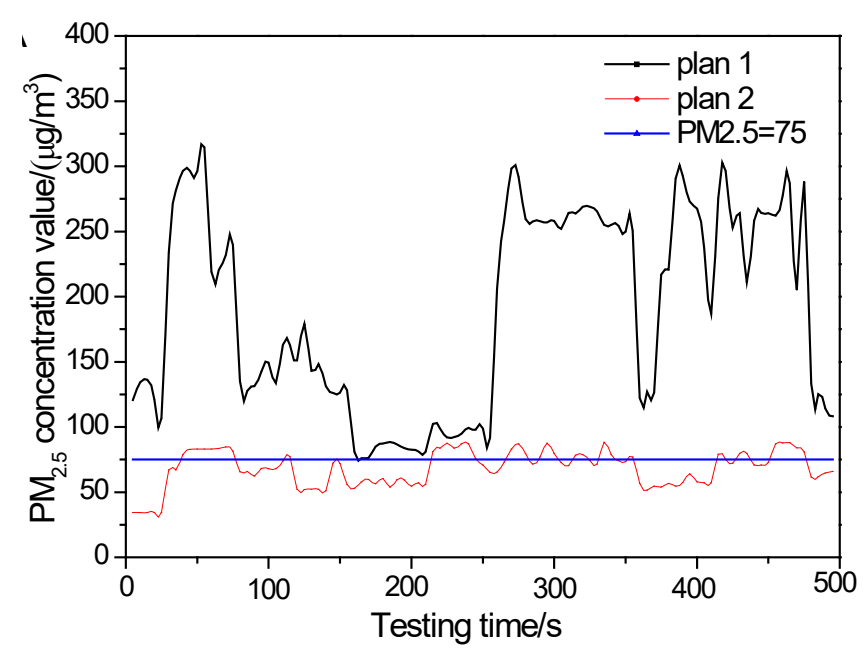

(A)

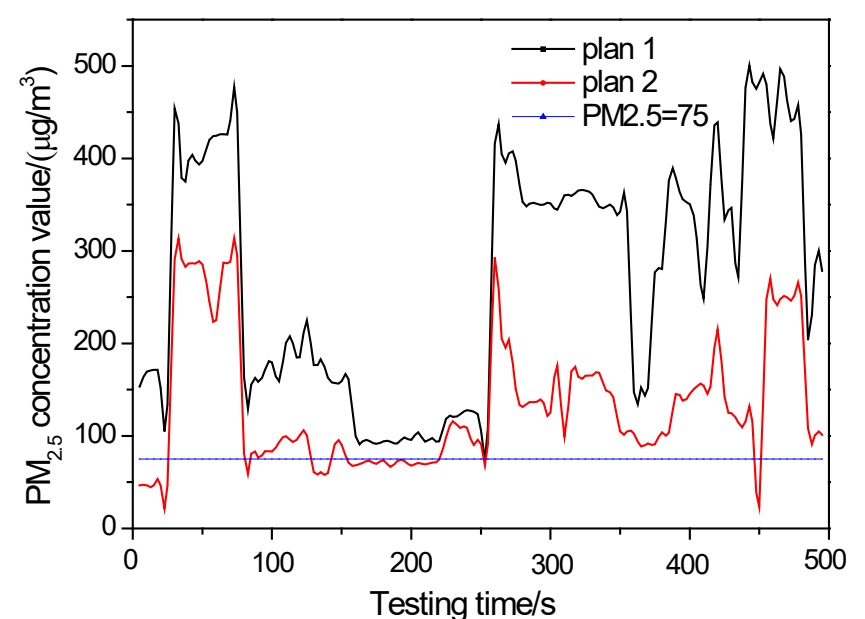

(B)

Fig. 8. $\mathrm{PM}_{2.5}$ mass concentration values at $(\mathrm{A})$ measurement point a and (B) measurement point $\mathrm{b}$ under two different ventilation control strategies. 
reduce the $\mathrm{PM}_{2.5}$ concentration at measurement point a (breathing zone) when the electric knife was turned on. The average reduction was about $200.0 \%$, and the $\mathrm{PM}_{2.5}$ concentration was close to $75 \mu \mathrm{g} \mathrm{m}^{-3}$, which basically met the personnel health requirements for ambient air. Thus, a small circulation purification system could significantly prevent medical hazards due to exposure to surgical smoke. For measurement point $\mathrm{b}$ (operation area), the $\mathrm{PM}_{2.5}$ value decreased by about $50.0 \%$, but the $\mathrm{PM}_{2.5}$ concentration values were all $>75 \mu \mathrm{g} \mathrm{m}^{-3}$, indicating that the fine particles in this area still exceeded the standard.

Through the real-time monitoring of the concentration of particulate matter in a clean operating room during operations, the clean operating room was determined to not be "clean" for the surgical staff during the operation. A small surgical smoke circulation purification system was proposed, but the entire design and control strategy must still be determined. The following are items for future studies. (1) Although the small surgical smoke circulation purification system significantly reduced the $\mathrm{PM}_{2.5}$ value in the doctor's breathing zone and effectively prevented occupational hazards, the $\mathrm{PM}_{2.5}$ concentration in the operating area was still beyond the standard, and there was a possibility of particle escape. Therefore, it is recommended to increase the barrier measures on both sides of the operating table, and doctors should wear protective masks. (2) Ignoring external factors, such as personnel movement and operation door opening during the test, it is recommended to establish a reasonable management system, manage items strictly, reduce personnel flow in the operating room, and establish automatic real-time particulate matter monitoring devices and emergency plans for different parts of the operating room.

\section{ACKNOWLEDGMENTS}

This work was sponsored by the China National Key R\&D Program during the 13th Five-Year Plan Period (grant number 2018YFC0705300), the National Key Research and Development Program of China (Grant No. 2018YFC0705201), and the National Natural Science Foundation of China (Grant No. 51878043).

\section{DISCLAIMER}

The author(s) declare no potential conflicts of interest with respect to the research, authorship, and/or publication of this article. Experimental data test to obtain authorization from relevant units.

\section{REFERENCES}

Applewhite, M.K., White, M.G., James, B.C., Abdulrasool, L., Kaplan, E.L., Angelos, P. and Grogan, R.H. (2017). Ultrasonic, bipolar, and integrated energy devices: Comparing heat spread in collateral tissues. J. Surg. Res. 207: 249-254. https://doi.org/10.1016/j.jss.2016.06.077

Bae, M.S., Park, J.K., Kim, K.H., Cho, S.S., Lee, K.Y. and Shon, Z.H. (2018). Emission and cytotoxicity of surgical smoke: Cholesta-3,5-diene released from pyrolysis of prostate tissue. Atmosphere 9: 381-388. https://doi.org/1 0.3390/atmos9100381

Baier, C., Adelmund, S., Schwab, F., Lassahn, C., Chaberny, I.F., Gosse, F., Vonberg, R.P. and Ebadi, E. (2019). Incidence and risk factors of surgical site infection after total knee arthroplasty: Results of a retrospective cohort study. Am. J. Infect. Control 47: 1270-1272. https://doi.org/10.1016/j.ajic.2019.04.010

Barrett, W.L. and Garber.S.M. (2003). Surgical smoke: A review of the literature. Is this just a lot of hot air? Surg. Endosc. 17: 979-987. https://doi.org/10.1007/s00464-0028584-5

Bensaha, T. (2013). A new approach for the surgical exposure of impacted canines by ultrasonic surgery through soft tissue. Int. J. Oral Maxillofac. Surg. 42: 1557-1561. https://doi.org/10.1016/j.ijom.2013.05.005

Bigony, L. (2007). Risks associated with exposure to surgical smoke plume: A review of the literature. AORN J. 86: 1013-1020. https://doi.org/10.1016/j.aorn.2007.07.005

Bree, K., Barnhill, S. and Rundell, W. (2017). The dangers of electrosurgical smoke to operating room personnel: A review. Workplace Health Saf. 65: 517-526. https://doi.org/10.1177/2165079917691063

Buonanno, G., Capuano, R., Cortellessa, G. and Stabile, L. (2019). Airborne particle emission rates and doses received in operating rooms from surgical smoke. Build. Environ. 151: 168-174. https://doi.org/10.1016/j.builden v.2019.01.044

Carbajo-Rodriguez, H., Aguayo-Albasini, J.L., Soria-Aledo, V. and Garcia-Lopez, C. (2009). Surgical smoke: Risks and preventive measures. Cir. Esp. 85: 274-279. https://doi.org/10.1016/j.ciresp.2008.10.004

Chavis, S., Wagner, V., Becker, M., Bowerman, M.I. and Jamias, M.S. (2016). Clearing the air about surgical smoke: An education program. Aorn J. 103: 289-296. https://doi.org/10.1016/j.aorn.2016.01.007

Chen, F.J., Wu, Q.Y., Huang, D.D., Zhang, Y., Lu, W. and Chen, M.M. (2018). Validation of the free area method for modelling fabric air dispersion system without orifices in computational fluid dynamics simulation. Indoor Built Environ. 27: 969-982. https://doi.org/10.1177/1420326X 17698532

Fan, C., Zhou, X., Su, G., Zhou, Y., Su, J., Luo, M. and Li, H. (2019). Risk factors for neck hematoma requiring surgical re-intervention after thyroidectomy: A systematic review and meta-analysis. BMC Surg. 19: 98. https://doi.org/10.1186/s12893-019-0559-8

GB3095 (2012). Ambient air quality standard. China Environmental Science Press, Beijing, 2012.

Golda, N., Merrill, B. and Neill, B. (2019). Intraoperative electrosurgical smoke during outpatient surgery: A survey of dermatologic surgeon and staff preferences. Cutis 104: $120-124$.

Heinsohn, P., Jewett, D.L., Balzer, L., Bennett, C.H., Seipel, P. and Rosen, A. (1991). Aerosols created by some surgical power tools: Particle size distribution and qualitative hemoglobin content. Appl. Ind. Hyg. 6: 773-776. https://doi.org/10.1080/1047322X.1991.10389727

Huang, Y., Zhou, X., Cao, B. and Yang, L. (2019). Effects 
of ventilation state of vertical shaft on fire tilt direction and smoke migration behaviours in a multi-storey building. Indoor Built Environ. 28: 790-805. https://doi.org/10.1177/1420326X18794767

Imani, R., Ladhani, L., Pardon, G., Wijngaart, W. and Robert, E. (2018). The influence of air flow velocity and particle size on the collection efficiency of passive electrostatic aerosol samplers. Aerosol Air Qual. Res. 19: 192-203. https://doi.org/10.4209/aaqr.2018.06.0211

In, S.M., Park, D.Y., Sohn, I.K., Kim, C.H., Lim, H.L., Hong, S.A., Jung, D.Y., Jeong, S.Y., Han, J.H. and Kim, H.J. (2015). Experimental study of the potential hazards of surgical smoke from powered instruments. $\mathrm{Br}$. J. Surg. 102: 1581-1586. https://doi.org/10.1002/bjs.9910

Kanter, W.R. (1992). The mutagenicity of electrocautery smoke-discussion. Plast. Reconstr. Surg. 89: 785-786.

Kuga, K., Ito, K., Yoo, S.J., Chen, W., Wang, P., Liao, J., Fowles, J., Shusterman, D. and Kumagai, K. (2018). Firstand second-hand smoke dispersion analysis from ecigarettes using a computer-simulated person with a respiratory tract model. Indoor Built Environ. 27: 898916. https://doi.org/10.1177/1420326X17694476

Kwak, H.D., Kim, S.H., Seo, Y.S. and Song, K.J.(2016). Detecting hepatitis B virus in surgical smoke emitted during laparoscopic surgery. Occup. Environ. Med. 73: 857-863. https://doi.org/10.1136/oemed-2016-103724

Lee, T., Soo, J.C., LeBouf, R.F., Burns, D., SchweglerBerry, D., Kashon, M., Bowers, J. and Harper, M. (2018). Surgical smoke control with local exhaust ventilation: Experimental study. J. Occupa. Environ. Hyg. 15: 341350. https://doi.org/10.1080/15459624.2017.1422082

Li, Y.D., Chen, D., Wang, F., Yuan, W., Zhang, Q.X. and Zhang, Y.M. (2013). An experimental study on the particle concentration and size distribution of smoke generated by flaming n-heptane. Appl. Mech. Mater. 391: 61-65. https://doi.org/10.4028/www.scientific.net/AMM.391.61

Mellor, G. and Hutchinson, M. (2013). Is it time for a more systematic approach to the hazards of surgical smoke? Reconsidering the evidence. Workplace Health Saf. 61: 265-270. https://doi.org/10.1177/216507991306100605

Mentese, S. and Tasdibi, D. (2016). Airborne bacteria levels in indoor urban environments: The influence of season and prevalence of sick building syndrome (SBS). Indoor Built Environ. 25: 563-580. https://doi.org/10.1177/1420 $326 \times 14562454$

Moot, A.R., Ledingham, K.M., Wilson, P.F., Senthilmohan, S.T., Lewis, D.R. and Roake, J. (2007). Composition of volatile organic compounds in diathermy plume as detected by selected ion flow tube mass spectrometry. ANZ J. Surg. 77: 20-23. https://doi.org/10.1111/j.14452197.2006.03827.x

Mosonik, B.C., Kibet, J.K., Ngari, S.M. and Nyamori, V.O. (2018). Environmentally persistent free radicals and particulate emissions from the thermal degradation of Croton megalocarpus biodiesel. Environ. Sci. Pollut. Res. 25: 24807-24817. https://doi.org/10.1007/s11356-018-2546-5

Nikaeen, M., Shamsizadeh, Z. and Mirhoseini, S.H. (2018). Direct monitoring of gram-negative agents of nosocomial infections in hospital air by a pcr-based approach. Aerosol
Air Qual. Res. 18: 2612-2617. https://doi.org/10.4209/aa qr.2017.11.0441

Okoshi, K., Kobayashi, K., Kinoshita, K., Tomizawa, Y., Hasegawa, S. and Sakai, Y. (2015). Health risks associated with exposure to surgical smoke for surgeons and operation room personnel. Surg. Today 45: 957-965. https://doi.org/10.1007/s00595-014-1085-Z

Peng, C., Tian, M., Chen, Y., Wang, H., Zhang, L., Shi, G., Liu, Y., Yang, F. and Zhai, C. (2019). Characteristics, formation mechanisms and potential transport pathways of $\mathrm{PM}_{2.5}$ at a rural background site in Chongqing, southwest China. Aerosol Air Qual. Res. 19: 1980-1982. https://doi.org/10.4209/aaqr.2019.01.0010

Pennock, J. (2020). Surgical smoke: Articulating the problem. AORN J. 111: P16-P17. https://doi.org/10.1002/aorn.12939

Ragde, S.F., Jorgensen, R.B. and Foreland, S. (2016). Characterisation of exposure to ultrafine particles from surgical smoke by use of a fast mobility particle sizer. Ann. Occup. Hyg. 60: 860-874. https://doi.org/10.1093/a nnhyg/mew033

Stocks, G.W., Self, S.D., Thompson, B., Adame, X.A. and O'Connor, D.P. (2010). Predicting bacterial populations based on airborne particulates: A study performed in nonlaminar flow operating rooms during joint arthroplasty surgery. Am. J. Infect. Control 38: 199-204. https://doi.org/10.1016/j.ajic.2009.07.006

Su, C., Wan, S., Chien, S. and Chen, Y. (2019). Performance verification and enhancement of mechanical smoke exhaust system in full-scale hot smoke test for a large space. Indoor Built Environ. 29: 180-195. https://doi.org/ 10.1177/1420326X19890903

Wang, Q., Luo, K., Fan, J., Gao, X. and Cen, K. (2019). Spatial distribution and multiscale transport characteristics of $\mathrm{PM}_{2.5}$ in China. Aerosol Air Qual. Res. 19: 1993-2007. https://doi.org/10.4209/aaqr.2019.04.0202

Wang, Y., Jia, C., Tao, J., Zhang, L., Liang, X., Ma, J., Gao, H., Huang, T. and Zhang, K. (2016). Chemical characterization and source apportionment of $\mathrm{PM}_{2.5}$ in a semi-arid and petrochemical-industrialized city, northwest China. Sci. Total Environ. 573: 1031-1040. https://doi.org/ 10.1016/j.scitotenv.2016.08.179

Watson, D.S. (2010). Surgical smoke evacuation during laparoscopic surgery. AORNJ. 92: 347-350. https://doi.org/ 10.1016/j.aorn.2010.06.010

Whyte, H.E., Raillard, C., Subrenat, A. and Hequet, V. (2019). Influence of environmental parameters on the photocatalytic oxidation efficiency of acrylonitrile and isoflurane; two operating room pollutants. Build. Environ. 154: 97-106. https://doi.org/10.1016/j.buildenv.2019.03.014

Wu, C., Zhang, H., Fu, S., Chan, K., Qin, D. and Chao, C.Y.H. (2019). Ultrafine particle emissions from a smouldering cigarette in a residence and its associated lung cancer risk. Indoor Built Environ. 28: 1396-1405. https://doi.org/10.1177/1420326X19841117

Wu, Y.C., Tang, C.S., Huang, H.Y., Liu, C.H., Chen, Y.L., Chen, D.R. and Lin, Y.W. (2011). Chemical production in electrocautery smoke by a novel predictive model. Eur. Surg. Res. 46: 102-107. https://doi.org/10.1177/1420326 X19841117 
Yau, Y.H. and Ding, L.C. (2014). A case study on the air distribution in an operating room at Sarawak General Hospital Heart Centre (SGHHC) in Malaysia. Indoor Built Environ. 23: 1129-1141. https://doi.org/10.1177/14 20326X13499359

Yau, Y.H. and Ding, L.C. (2015). A comprehensive computational fluid dynamics simulation on the air distribution in an operating room at University of Malaya Medical Centre Malaysia. Indoor Built Environ. 24: 355 369. https://doi.org/10.1177/1420326X13516349

Zahir, M.Z., Heo, J.E. and Yook, S.J. (2018). Effects of three-partitioned horizontal inlet and clean air on collection efficiency and wall loss of slit virtual impactors. Aerosol Air Qual. Res. 18: 1131-1140. https://doi.org/10.4209/aa qr.2017.12.0563
Ziegler, B.L., Thomas, C.A., Meier, T., Muller, R., Fliedner, T.M. and Weber, L. (1998). Generation of infectious retrovirus aerosol through medical laser irradiation. Laser. Surg. Med. 22: 37-41. https://doi.org/10.1002/(SI CI)1096-9101(1998)22:1<37::AID-LSM9>3.0.CO;2-Y

Zoon, W.A.C., Loomans, M.G.L.C. and Hensen, J.L.M. (2011). Testing the effectiveness of operating room ventilation with regard to removal of airborne bacteria. Build. Environ. 46: 2570-2577. https://doi.org/10.1016/j. buildenv.2011.06.015

Received for review, May 13, 2020

Revised, August 23, 2020 Accepted, September 4, 2020 